\title{
ONTOLOGÍA Y NIHILISMO
}

\author{
Teresa OÑATE \\ $U N E D$
}

Entrevista a Gianni Vattimo en Estrasburgo. Julio de 1999

Hacía mucho calor, pero no se veía el sol en el cielo. Europa aún se desangraba por el Este bajo el rígido control previsto de sus rentables guerras, y la banca se disponía ya al ingente negocio de la salvación - reconstrucciónmoderna de lo hundido, casi sin esperar a que los bombardeos humanitarios trocaran puntualmente en campos de escombros las viejas culturas, las milenarias ciudades. Ya nadie creía que el fondo de la cuestión coincidiera con los complicados dramas étnicos y religiosos de las identidades románticas en pugna, salvo quizá las tristes mujeres y los hombres tristes que, apenas hace nueve años, al comienzo de la última década del último siglo, en el año 90 , creyeron poder reiniciar el tejido político-espiritual -hacía tanto interrumpido por la U.R.S.S. - , de sus culturas y memorias sometidas. Ahora vagan como espectros atónitos por entre los campos de refugiados, las hostilizadas chabolas de las ciudades nuevas y los improvisados cementerios. Su insólita pretensión de memoria ha durado un parpadeo, su anacrónica pretensión de sentido ha valido varios genocidios que, a ojos de los jueces, han de repartirse equitativamente entre todas las minorias: las incapaces, por no saber gestionar el espacio político o el proceso de paz. Son culpables de su propia guerra. Ni siquiera sus muertos han sido más que fantoches ignorantes. Muertos equivocados y pueblos erráticos en éxodo, bajo el fuego sin luz de este julio europeo, «en que la Europa blanca y limpia expurgada, prosigue su política exclusiva e integrista hacia la futura coalición de identidades nacionales, de espaldas a una coalición multicultural y multirracial», para decirlo con palabras del lúcido Realanalyse que el filósofo postmoderno Jean Baudrillard opone a la Realpolitik de una "guerra que es un engaño, que se hace por otra cosa, y cuyos objetivos 
están ocultos, inconfesados y quizá incluso obscuros, para la conciencia de unos y de otros. Sería una ingenuidad olvidar las razones cínicas y secretas de esta guerra, que tratan de ocultar por todas partes, los comentarios ideológicos, intelectuales y humanitarios» (J.BAUDRILLARD, "Razones ocultas de la guerra", Diario El Mundo, 3/5/1999, p. 10). Exactamente en el mismo sentido se han pronunciado también otras voces: el Gobierno Canadiense, Cruz Roja Internacional, y muchas O.N.G.s: las únicas que han intervenido en auxilio de la población civil en lugares de alto riesgo. Dice Jacky Mamou, presidente de Médicos del Mundo, denunciando las cifras, que en la Primera Guerra Mundial se registró un 5\% de muertos entre la población civil, mientras que en esta guerra privatizada y amenizada por las mafias, los muertos civiles ya alcanzan el 90\%. (J. MAMOU: "Au nom de l'humanitaire", Le Monde Diplomatique, 543, junio 1999, p.32). Vamos progresando, no cabe duda: ya ni siquiera la guerra tiene límites.

Pero los intereses de la mundialización y el juicio de la racionalización progresista son inapelables. Estados Unidos ha controlado su inflación y el euro se está recuperando ya antes de nacer a la circulación. Mientras tanto Schrröder propone una nueva economía sin despilfarro, y Felipe González, el torpe expresidente terrorista, se muestra partidario del progreso global. Monsieur Chirac, el actual presidente de la República Francesa, por su parte, ha hecho público antes de ayer, aquí, en Estrasburgo, su proyecto de fundar en breve un Ministerio de la Historia, o Ministerio de la Memoria, sobre el que se levantaría la conciencia de la Nueva Europa, encargada de vigilar y castigar cualquier revisionismo: una cosa es la obligada Unidad Europea y otra que podamos olvidar los crímenes del nazismo, "porque la bestia duerme en cada uno de nosotros", citaba la edificante prensa de Le Figaro el 18/7/1999. Ni en la Francia contraria al desarme atómico, ni en el Irán que tiene a su propio presidente Jâtami al borde de la carcel, junto con sus 250 estudiantes ya en presidio, se puede ser contra-revolucionario, mientras que en Chiapas no ser revolucionario constituye la única posibilidad lúcidamente proseguida por el subcomandante Marcos, ese postmarxista que funda la ilusión de tantos para exasperación de la coartada del orden. En nombre de la ley los ejércitos paramilitares voluntarios podrían desfigurar impunemente el rostro de las mujeres que salgan descubiertas a la calle en Teherán. En nombre de la ley algunas librerías de Estrasburgo informan así a los turistas en los stands de historia: hay el anaquel con los libros de historia de Italia, de Suecia o de Turquía, y hay también un curioso anaquel de nombre compuesto: Alemania-Nazismo; denunciarlo es 
filo-nazi. Nadie puede preguntar: en tal caso se sería juzgado por revisionismo, de uno u otro signo.

Nadie podría adivinar tampoco el llanto de Bosnia o la miseria de Kósovo en el hipermoderno aeropuerto de París. Nadie podría tolerar la colorida presencia de los balcánicos errantes entre las asépticas y titánicas estructuras del Parlamento de Estrasburgo, la nueva capital de Europa: la sociedad transparente del trabajador cibernético bien educado, contra cuya violencia se levanta, también ahora, el discurso debolista de un filósofo hermenéutico que es, desde hace no mucho, diputado europeo y representante de la izquierda democrática italiana: el profesor torinés Gianni Vattimo, cuya crítica comprometida se orienta a disolver, desde dentro, las estructuras fuertes de la modernidad, entrando en el terreno de su mismo espacio político, hoy en crisis de legitimidad.

A través de los enormes ventanales del despacho de Gianni Vattimo, en el edificio del Nuevo Hemiciclo del Parlamento de Estrasburgo, se ven urbanizaciones de chalets pareados con pulidos tejados alsacianos. Son todos idénticos y dibujan hileras de puzles cubriendo las colinas desnudas de arbolado. Estoy impresionada por el edificio de cristal y acero aéreo, flotante, de dimensiones colosales, que alberga en su interior una ciudad de ciencia-ficción. El mundo parece haberse convertido en una oficina silenciosa; pienso en un Kafka lavado por Rothko, y en la moqueta gigantesca que concentraba la única cromática de este universo de pantallas en uno sólo de los bares de ¿la décima planta?: sobre el suelo negro, cubierto por ella, se imprimían bajo los pies de los políticos rutilantes plantas tropicales de verde ácido, anémonas bermellón y aplastados papagayos amarillos; fuera de su descomunal perímetro radioactivo se acababa la Naturaleza, y volvía a reinar el gris infinito cortándose en paneles.

Hace varios días que estamos en la ciudad. No habíamos vuelto a encontrarnos desde la primavera del 98, en que Gianni Vattimo vino a Madrid, entre otras cosas, a dictar una lección magistral en el Paraninfo de la Facultad de Filosofia de la Universidad Complutense, y a tener una mesa redonda con los más de trescientos estudiantes y profesores que pudieron lograr entrar en el aula, claramente inadecuada al evento. Ya en aquella ocasión tuvimos oportunidad de discutir bastante y con calma, después, a propósito de muchas de las cuestiones que se habían suscitado en los encendidos debates, sobre todo, de aquella larga y eléctrica mesa redonda. La conferencia de Vattimo versó sobre "La tentación del realismo", y la pestaña del programa de aquel Encuentro con Vattimo del 26 de marzo de 1998 seleccionaba este texto suyo: 
"... Éste es el sentido nihilista de la hermenéutica: si no pensamos que la transición de la metafísica de la presencia a la ontología de la proveniencia es la corrección de un error, sino el acaecer del ser mismo como indicación de su destino, entonces la tendencia al debilitamiento que este proceso manifiesta, puede ser interpretada como verdad del nihilismo, desde Nietzsche y desde el pensamiento del sentido de la muerte de Dios; es decir, desde el sentido de la disolución de la verdad como evidencia perentoria y objetiva. Hasta el momento los filósofos han creído describir el mundo, ahora es tiempo de interpretarlo..." ".

El último Vattimo, el de la kenósis del Creer que se cree, mostraba, así, la coherencia del enlace entre el cristianismo kenótico y el nihilismo nietzscheano de la primera época postmoderna, a través del debilitamiento del ser. Estas intervenciones en Madrid coincidían con unos Seminarios celebrados en Lovaina y Bogotá sobre La Realidad, y subrayaban la dimensión ontológica de la hermenéutica, en crítica explícita con los que quieren hacer de ella una mera epistemología: una teoría de la interpretación como teoría del conocimiento o teoría del comentario literario. Las implicaciones políticas de la discusión también son relevantes, y Vattimo pudo comprobar una vez más en Madrid la seria dificultad que experimentan muchos de los españoles de las generaciones nacidas antes de los años sesenta para entender la izquierda nomarxista y no-atea; comentábamos cómo a menudo muchos españoles comprenden (ya con simpatía, ya con rechazo), la Teología de la Liberación y la Iglesia de los pobres hispanoamericana, por caber dentro del marco del marxismo cristiano, mientras que, sin embargo, todo lo que no sea marxista les parece inmediatamente de derechas. En esa densa capa freática, más bien popular o tópica, se localiza, sin duda, la impermeabilidad de gran parte de las generaciones anteriores a los planteamientos izquierdistas de la postmodernidad, que es postmarxista, por una parte, y ontológico-teológica por otra, ¡nada menos! Nos reíamos pensando que, desde tal planteamiento, el Spinoza del Tratado Teológico-Politico y del amor Dei intelectualis tendría que ser de derechas, y de cómo dentro de poco algunos ilustrados-marxistas españoles publicarían, tal vez, un Índice de filósofos-nazis censurados: desde Spinoza a Nietzsche, Heidegger, Gadamer, Deleuze, Vattimo, Lyotard, y la postmodernidad entera: Foucault, Rorty, Derrida,... con gran y secreto regocijo de la verdadera derecha absorta en la contemplación de la hoguera: ¿volverían a quemar a Giordano Bruno con tal de mantener las provinciales divisiones de la izquierda y la derecha propias del franquismo y el neofranquismo? Pero aún 
administran los medios de comunicación pública como un coto de caza privado dentro de su propia finca.

Apenas un mes más tarde de aquél encuentro murió Jean-François Lyotard, a las puertas de mayo del 98, como si la melancolía ritual de este hombre, uno de los más profundos y honestos pensadores del siglo XX, el inventor de la postmodernidad filosófica, no quisiera tener que ponerse otra vez de luto, ahora por aquél mayo de treinta años atrás. En la Universidad Complutense, el decanato del profesor Maceiras, quien vivió el 68 y es tan buen conocedor como propiciador del pensamiento francés contemporáneo, tardó sólo unos dias, llevado por una agilidad y disponibilidad exquisitas, en organizar una jornada de duelo en Homenaje a Lyotard, el 6 de mayo de 1998, que algunos de los palímsestos tuvimos el honor de coordinar. Desde que la Facultad de Filosofía abrió sus puertas antes de las nueve de la mañana, hasta que las cerró después de las diez de la noche, fueron sumándose al luto de aquella capilla ardiente intelectiva cuantos querían pensar a Lyotard y con Lyotard; hubo ponencias de estudiantes de todos los niveles, que a veces hacían admirarse a los profesores por su creatividad y preparación; hubo conferencias informadas, discusiones precisas, y Universidad. Pero hubo, sobre todo, filosofia, alrededor de un pensamiento que articulaba con otro estilo los diversos campos y problemas de la filosofia política actual, haciéndolos desembocar en la postmodernidad estética: del psicoanálisis a la filosofía analítica, del estructuralismo a la hermenéutica, pasando por la larga despedida del marxismo como lazo de legitimidad social, ya no vinculante, en las sociedades y culturas de postmoderna condición tras el fin de los grandes metarrelatos.

Todavía estuve trabajando en el Retorno de lo divino en la postmodernidad durante algún tiempo, dedicada concretamente a profundizar en el estudio del pensamiento del último Schelling, porque tal referencia me parece cada vez más necesaria para comprender el planteamiento de la hermenéutica de Vattimo, respetando la matizada complejidad que desenvuelve. Tuve la fortuna de que Félix Duque publicara por entonces su Historia de la Filosofia Moderna. La era de la crítica (Madrid, Akal, 1998), uno de esos libros asombrosos, excelentes, que parecen constituir por sí mismos un mentis ontológico a cualquier desánimo en el trabajo racional, y muestran por sí solos el brillo y el vuelo riguroso que ya tiene entre los filósofos españoles contemporáneos el renacimiento de la mejor filosofía. Véase la obra; todo elogio resulta mezquino. Pues bien, en ella, en este libro filosófico que repiensa la historia del pensamiento moderno, dedica el profesor Duque al último Schelling, en 
su último capítulo, una monografía muy documentada, pero más sugerente aún, que permite una lectura de los textos originales de Schelling, vivamente suscitada. Sólo una vez realizada ésta estuvo listo El retorno de lo divino en la postmodernidad, tras lo que procedí a las últimas correcciones y revisiones antes de enviar el manuscrito a Vattimo.

Los dos queríamos grabar, antes de publicarlo, una Entrevista en que el filósofo debolista comentara libremente algunas de sus impresiones tras la lectura del este ensayo. Pensar hoy requiere, desde el punto de vista de la hermenéutica, pensar a través de los textos de otros, a través de su comentario, traducción, versión, distorsión, prosecución e interpretación crítica. No parece demasiado a tono con el estilo de la racionalidad hermenéutica, enarbolar la pluma en nombre del sujeto propio de soñada autogénesis. Se trata, por el contrario, de dejar aparecer la dialogicidad no dialéctica, concediendo espacio a la recepción, la gratitud y la virtualización de la alteridad discursiva que transforma mutuamente la interlocución; sin tales criterios no puede entrar en juego efectivamente la acción comunicativa del pensar, y ello, desde luego, porque no cabe ni siquiera hablar de crítica con verdadero disenso concreto: el capaz de localizar la topología y genealogía de los cruces, en recíproca destitución diferencial. Pero que la racionalidad dialéctica es monológica, y reserva sin más la legitimidad o la victoria al que viene después y tiene, sólo por eso, la última palabra, que se monta por encima de la anterior legitimándose en la mera crítica de la que da por posición pasada o superada, ya ha sido suficientemente denunciado por las páginas de este libro como recusación de la violencia y generalidad autoproyectivas propias de la dialéctica en todos los órdenes. Probablemente en este punto radique lo que hay de inconmensurable entre dialéctica y hermenéutica como dos épocas discontínuas de la racionalidad del ser: entre el carácter abstracto de la negación e inquisición como saturación de la crítica, y el estatuto afirmativo de la relación también cuando se trata del disenso de la diferencia, pues sólo esto último restituye a la afirmación, a la paz y a la amistad una dimensión racional creativa, ontológicamente anterior y superior tanto a la confrontación de la afirmación y la negación en el juicio de los opuestos, como a los pactos de la prudencia.

La hermenéutica rememora, así, el lugar incondicional de la tesis como afirmación no dogmática. De-vuelve a la tesis la palabra, y des-cubre un lugar, anterior al conflicto, que es posibilitante del conflicto: una diferencia-relacional que no hace síntesis porque no se recubre de concepto, ni es absorbida en el concepto como si fuera un mero predicado. Se trata del lugar indisponible 
de la discusión, cuando ésta sí es verdaderamente posible en el disenso. A esto llama Gianni Vattimo, a veces, dislocación de la proveniencia; y a veces, dotando al término de una dimensión esencial que no se explicitaba tanto en el pensamiento de Gadamer, y no lo hacía como paradoja, lo llama pietas como perversión de la pietas durativa; de este modo nos aproxima la hermenéutica actual a los sentidos, también estéticos, del Andenken de Heidegger, permitiendo aparecer una relación insólita no ya sólo entre el Andenken y el eterno retorno, pues ésta resulta más accesible, sino entre el eterno retorno y el principio de no-contradicción. Sólo entonces, cuando este pensamiento sea posible para muchos, estará la civilización dialéctica en condiciones de asumir la misma muerte de la que establemente vive su historia congelada; porque podría ser, entonces, que la saeta de un remoto centauro, aquél que hiere desde lejos, se hubiera clavado como una estaca en el corazón sanguinario del vampiro. Amanecería, entonces, la risa de los niños en la playa de Las palabras y las cosas, y la marea azul del curvo cuerpo de la tierra celeste arrastraría, hacia el atrás silente del océano, las huellas salvajes de la civilización del Hombre en la época histórica de la guerra total; aquella época desmesurada y monstruosa en que el Hombre quiso ser el único Dios. Que el mar escuche, con alegría el rezo, de todos los que rezan por la muerte del hombre y el retorno de lo divino, en todas las lenguas... Quizá esta sea la plegaria del siglo XXI.

Por el momento resulta imprescindible volver a abrir los espacios de discusión filosófica viva. Vattimo ya ha leido este libro. Hemos quedado en Estrasburgo para trabajar en la entrevista, en los huecos que dejan las obligaciones del Parlamento. Ahora se trata de volver a escucharle, para aprender tanto de su crítica como de los relieves del disenso, centrando la atención en lo impensado preciso de la interlocución, para asomarse a los lugares excluidos por la trasnformación de los límites que hacen posible este discurso. Vattimo habló, en este caso, justo una hora grabada que refleja, a su modo, las discusiones de trabajo y las largas conversaciones de los hermosos dias de Estrasburgo por lo que a su amistad exquisita se refiere. He tratado de respetar, con la mayor literalidad, la vertiginosa calidez de su voz y el ritmo riguroso de su acento; grabamos de una vez, sin una sola interrupción. En general es casi imposible verter la continuidad veloz de la mente-cuerpo oral, y su estar pensando como acción expresiva, en la lenta escritura de los signos planos sin que se pierda el alma viva de la música; pero si se trata de este piamontés, apasionado por la filosofía del presente, que no se detuvo ni a beber un sorbo de agua mientras trazaba volúmenes inquietos o remansados con las 
manos, y devanaba con la frente abierta madejas meteóricas hasta las fugas del silencio hondo de un segundo, la traducción no puede, en absoluto, dar idea del discurso. Ahí va lo que queda de él al trasladarlo al soporte que lo miente para hacerlo durar en otros lugares. Todos aquellos que pueden multiplicar la discusión.

Teresa Oñate.-Hablando en general, y en relación al poso que te haya dejado sencillamente la lectura: ¿en qué ocasiones hermenéuticas te has sentido más distante de este libro; ¿qué tendrías que matizar, añadir o corregir en cuanto a la reconstrucción que el texto hace de tu itinerario intelectual diverso?

Gianni Vattimo.-Sí, de esto hemos hablado bastante, y tú estás perfectamente al tanto, por lo que a mí se refiere, de qué es lo que ha sucedido. El problema está en cómo evalúas e interpretas tú esa transición que parece entrañar un retorno teológico o religioso, y que yo no alcanzo a explicarme si no es a través de la siguiente idea: la de cómo el pasaje por mi parte a un renovado interés religioso deriva de una especie de autoexamen en el cual la pregunta decisiva se ciñe a inquirir por qué sea preferible una versión débil de la ontología de Heidegger. Esto es algo que me he preguntado yo mismo a menudo, o sea, ¿por qué es preferible interpretar a Heidegger como yo lo hago, es decir, a la manera nihilista propia del debilitamiento? Podría parecer, en principio, que falten en Heidegger razones lo suficientemente concluyentes como para justificar tal opción, y, desde luego no se puede ignorar que se han dado muchas otras interpretaciones de Heidegger distintas de la mía, las cuales me parecen, como mínimo, tan legítimas como la que defiendo. Por mi parte, he comenzado a justificar una lectura debolista de Heidegger insistiendo en el hecho de cómo su abandono de la fenomenología en los años diez-veinte, tuvo que ver más con razones de índole ética que con razones de orden teórico.

Ya en Sein und Zeit, y antes, estaba el rechazo de la concepción descriptiva del ser, es decir, de la idea de la verdad como correspondencia, pero Heidegger no podía ponerse a refutar la idea metafísica del ser sobre la base del hecho de que ésta no describiera adecuadamente al ser; para él, este problema no habría podido tener el menor sentido. Pues bien, según creo haber escrito en alguna parte y me parece importante subrayar aquí, he comenzado a leer a Heidegger, 
entonces, desde la clave de considerarle también como a un pensador de la vanguardia de los años diez, esto es, en analogía con Bloch, aunque obviamente haya entre ellos un sin número de profundas diferencias; sin embargo, las razones por las cuales Heidegger refuta la idea metafísica del ser remiten a los mismos motivos y tensiones por los que Bloch se ponía de parte del expresionismo, a saber: hay un peligro inminente de organización racionalizada total de la sociedad, que se hace muy presente en torno a la primera guerra mundial, y contra el cual Bloch reacciona escribiendo Der Geist der Utopie, al igual que Heidegger reaccionará más adelante escribiendo Sein und Zeit. Esto dicho muy genéricamente, pero creo que si no se tiene en cuenta, no se entiende por qué Heidegger tenía que buscar una concepción del ser que fuera diversa de la concepción metafísica del ser: no porque le interesara una concepción más verdadera, sino por razones que han de definirse, por tanto y como decía, en términos ético-políticos y no teóricos. Es, pues, desde este punto de vista desde el que me parecía legítimo proseguir y desenvolver hasta sus últimas consecuencias una lectura de Heidegger que respondiera a esta exigencia. Supongamos, por ejemplo, que leemos a Heidegger en clave de teología negativa, como yo mismo en insistido en denunciar que se ha hecho muchas veces: hay el ser pero nosotros no lo alcanzamos, etc. Su problema, digamos, de contrastar la sociedad de la organización total ¿se resuelve o no? No lo parece, desde luego, porque resta intacta la posibilidad de una autoridad cualquiera que venga a hablar en nombre de ese ser, etc. El problema, en suma, que uno se plantea viendo a Heidegger dedicado a renovar el pensamiento del ser, es el siguiente: si no es por razones descriptivas, ¿por qué es, entonces? Por otras razones que no pueden desligarse, además, de la idea según la cual es precisamente el ser como objetividad el que funda la sociedad totalitaria. Pero que el ser como objetividad funde la sociedad totalitaria se debe a que, en el fondo, es un ser violento, o sea, el ser delante del cual ya nada cabe preguntar. Con lo cual, según me parece, está lejos de no tener sentido el enfoque que se propone leer e interpretar a Heidegger a la luz de esta exigencia, que yo considero decisiva para él por mucho que él mismo haya podido olvidarla a veces, y muy probablemente al menos, cuando se hizo nazi en el 33; quizá porque en ese momento empezara a pensar que podía darse un retorno del ser en una cultura determinada, y más concretamente en aquella que para él se asemejaba más a la griega, es decir: la Alemania de los románticos. Está toda esa temática de la vecindad entre Alemania y la Hélade que impregna la cultura germana hasta el nazismo. Sin embargo, y por contraste, si uno sigue hasta el final la idea de 
que el ser metafísico viene sobrepasado porque es violento, se abre en este punto a una serie de consecuencias muy distinta. Pues bien, si he comenzado a leer a Heidegger al modo débil es porque me parece poder corresponder así, efectivamente, a esa exigencia profunda que considero la línea directriz de su pensamiento, de acuerdo con aquello que Pareyson llamaba la forma formante. el alma del pensamiento de Heidegger, contra la cual pueden encontrarse sin duda textos y piezas de la obra de Heidegger explícita, que forman parte de un pensamiento complejo sometido a autocrítica y autoconfrontación.

Después he seguido adelante con este discurso sobre la violencia, debido también a que, desde luego, naturalmente, a mí la violencia... no me va bien nunca y no me parece nunca bien. Pero, ¿y en el caso de Heideggẹr? ¿Desde dónde se oponía él a la violencia? ¿En nombre de qué? Y es entonces - cómo decir- es entonces cuando he comenzado a considerar que si yo optaba por un pensamiento no violento, y por tanto no metafísico - pienso en la lectura del Derrida de Metafisica y violencia, en Levinas, etc.- era porque, en última instancia y ante todo, quería una ética de la amistad. En esa época pensé mucho en Schopenhauer, en la idea según la cual el ser de Heidegger se oponía a la metafísica como la ética de Schopenhauer se oponía a la voluntad de sobrevivencia, a la lucha por la existencia, etc. $Y$ esto aún me sigue pareciendo relevante hoy. Al final de ese proceso me vi obligado a reconocer, sin embargo - aunque todavía no sé bien a través de qué vías, probablemente de orden biográfico-, que en la opción por un ser no metafísico, o un ser débil, se implicaba un considerable complejo de razones de origen religioso. Entonces fue cuando empezó a cobrar importancia para mí considerar que quizá tampoco para Heidegger hubiera sido indiferente el provenir de una formación cristiana, y, ya a partir de este momento, se fue desenvolviendo, poco a poco, la vía discursiva del pensiero debole, si bien no tan directamente, o al menos inicialmente no de un modo tan claro; la prueba está en que aún el primer ensayo que compuse en los 80 , que trata sobre Violencia y diferencia, y que precede a los textos donde se expresan las tesis del pensamiento débih no estaba todavía referido de un modo explícito a la religión, aunque sí se vinculara ya a la exigencia de pensar el ser por la vía de la reducción, el debilitamiento o la disolución.

El discurso del debilitamiento se fue complicando desde entonces con otros factores; por ejemplo, con el conocimiento de R.Girard —acuérdate de mi recensión del texto de Girard en el otoño del 83-84. Girad no podía dejar de interesarme, porque, en efecto, su discurso sobre el cristianismo no victimario 
contenía, a mí parecer, instancias también de mucha importancia para mi trabajo. Sobre todo el que, desde su perspectiva, se pudiera pensar el cristianismo como una religión antirreligiosa, en el sentido de ser una religión en la cual se anuncia que lo divino - tal y como siempre había sido pensado por la tradición humana: por los judíos, los católicos, etc.- es una cosa supersticiosa, mientras que la encarnación de Cristo es algo muy distinto. Este discurso se ha desarrollado para mí, después, en el sentido de la secularización, esto es, he comenzado a pensar, contra Girard, que también la modernidad es un modo de alejarse de esa visión transcendente de Dios - mientras que Girard no estaría de acuerdo con ello, porque según él sigue habiendo diversas razones vigentes para sostener que alguna forma simbólica de sacrificio, cualquiera que ésta sea, debe mantenerse inevitablemente si es que se quiere poder regular la rivalidad generalizada y la violencia de todos contra todos. Yo, por el contrario, creo que todo este núcleo victimario y sacrificial violento debe disolverse de continuo, igual que debe consumirse la idea del ser como estabilidad, objetividad, etc.

Hasta aquí, pues, las razones de la transformación que experimenta mi itinerario. Yo no sabría localizar ahora exactamente cómo las describes tú en el libro, pero si lo recuerdo bien tengo la impresión de que tú fueses un poco más brusca en este punto, o sea, que vinculases todo esto a una especie de retorno religioso que se difunde por Europa. Hay, por ejemplo, un libro interesante Teologia de la fenomenología, de J. Nicau, al que he conocido personalmente no hace mucho, en el que se discute muy asperamente el pensamiento de Jean Louc Marion, el cual, como sabes, es una especie de filósofo cristiano muy cultivado, muy famoso, que da un Seminario en Baviera, en un centro teológico hebraico que se llama el Centro Rosenzweig, y con el que todos los hebreos religiosos se sienten perfectamente a gusto. Les encanta el discurso de Marión. ¿Qué clase de discurso? Marión termina por hacer un discurso fenomenológicoreligioso, pero de tipo metafísico, en cuyo fondo hay siempre ese algo donado que se me da, y el énfasis fenomenológico en el dato como donato; ya se que parece un juego de palabras, desde luego en italiano, pero también en castellano, en francés o en alemán. Porque cuando se dice "es gibt Sein", "el ser que se do", parece que el sólo hecho de darse como donarse involucrara súbitamente un aura religiosa que lo envuelve todo: el dato deviene algo que se aguarda, aparece el otro de Levinas como exterioridad; y, en fin, toda esta retórica al uso que yo encuentro, en primer lugar, bastante poco aceptable desde el punto de vista heideggeriano, además de muy poco religiosa, muy metafísica y tendencialmente muy 
supersticiosa, del retorno a formas de religiosidad autoritaria; después de todo, no es extraño que se trate de filosofos papales, amigos del Papa, de los Cardenales, etc. Pero aquí no se trata de hacer una crítica a Marion, sino de dejar claro que las razones de mi reproposición del cristianismo, así como las razones de mi propio reencuentro con la realidad cristiana - yo he tenido formación católica durante muchos años, durante veinticinco años he sido católico practicante- nada tienen que ver, en ningún caso, con esa especie de retorno fenomenológico a la objetividad. Hay un filósofo alemán que también estos días participaba en ese Seminario que te decía, y que hablaba de San Anselmo, y de Heidegger y Husserl, naturalmente; dentro de poco santificarán a Husserl, porque todo este retorno de lo objetivo desemboca en esa dirección. Pero yo no soy devoto de San Anselmo.

He llegado, en suma, a una religión paradójica, sin duda vinculada a mi personal tradición e implicación dentro del juego político en Italia, porque, para empezar, como católico he sido siempre algo más que un anticonformista; de hecho, desde los años cincuenta he militado en la izquierda, y además estaba con el pensamiento gay, contra las prohibiciones del Papa y los Obispos italianos, y contra su pretensión de imponer la ley de la iglesia católica como base de la ley civil: aborto, inseminación artificial, eutanasia, etc.; cuestiones que para los parlamentarios que fueran católicos estaban decididas de antemano por la dogmática y la moral impuesta desde los prejuicios teológicos no revisados de una cierta moral. Para mí todo esto ha tenido particular importancia, y quizá por eso insisto tanto en ello. Quería recomenzar a leer el Evangelio sin necesidad de tener que pasar por esta serie de, si no de estupideces, sí demasiado discutibles prescripciones ético-dogmáticas del Papa. Ahora bien, lo mismo podría decir desde la perspectiva político-cultural, que me ha llevado al mismo punto, es decir, al convencimiento de cómo la filosofía se vuelve algo casi completamente ineficaz si interrumpe su relación y controversia con la Iglesia y la religiosidad.

A menudo me acuerdo de una protesta que suele repetir Rorty cuando discutimos: "bistoria del ser, historia del ser - dice-, tanto revuelo y cientos de libros, cuando el ser es una palabra que apenas quiere decir algo para unas dos mil personas..." ¿Y es verdad!, mientras que la historia del Cristianismo, la Iglesia, la misa, la confesión, etc., son épocas de la historia del planeta. Descartes tendría que ser relatado más modestamente... Bueno, ahora en serio: en cualquier caso, estoy particularmente convencido de que si la filosofía se entiende en un 
sentido actual o militante, y no sólo se le adscribe un cometido históricoarqueológico, debe pasar a través del encuentro y des-encuentro con la religión, entrar en confrontación con ella. Hoy, por el contrario, en las filosofias de casi todas las corrientes, se coloca la religión en una parte y la filosofía en otra, y ni siquiera se trata de su sobreposición; si se habla de religión no se habla de filosofia, y viceversa. El caso de Ricoeur, por ejemplo, me parece muy significativo a este respecto, y a menudo me hace reflexionar en los problemas de esta orientación. ¿¿Por qué habla siempre como si hubiese dos discursos? Además parecería que la demarcación entre ellos pudiera establecerse con tanta claridad como para darse incluso por supuesta, sin siquiera necesidad de ser abordada. También es verdad que cuando se suponen dos discursos siempre hay luego un tercero que habla de los otros dos; pero, ¿y este metadiscurso?, ¿no debería poder justificarse?. No sé hasta que punto sea Ricoeur ni consciente ni fielmente representativo de esta posición, pero me parece legítimo preguntarlo, porque, lo cierto es, de todos modos, que la filosofía siempre está dispuesta a hablar del mito, mientras que, al revés, casi nunca o nunca le toca al mito hablar de la filosofía, lo cual localiza una presunta superioridad racional de la filosofía en su acercamiento al campo mítico y religioso, cuando llega, si llega, a reconocerlos como campos. Pero si cuando lo hace es situándose inmediatamente en el papel del que manda, la especie de pacifismo neutro que al parecer se quería hacer reinar entre los dos discursos independientes, enmascara una situación distinta, que, en último término, viene a declarar que de religión no se habla, o ya no se habla. Sí, claro está que hay un montón de gente que va a la iglesia, desde luego, pero se trata de algo semejante a lo que ocurría con el arte en tiempos de Hegel, a saber: que es algo superado, y ya está; nada tiene que ver con la verdad. Pero si la filosofía - me parece a mí y este sería justo el problema - se seca y esteriliza, en cuanto no trata siquiera polémicamente de temáticas religiosas, hasta el punto de llegar a rallar la ineficacia, la cuestión toma otro cariz; la filosofía deviene entonces epistemología críptica, útil a lo sumo, para seleccionar otros licenciados que repiten a los ufanos mandarines, y son obligados por éstos a encerrarse en unos debates tan eruditos como autorreferentes, los cuales, desde luego, eso sí, poco tienen que ver ya con la política. La filosofía, en efecto, deja entonces de ser filosofia politica, porque lo político, desde luego, ha de atravesar por un cierto consenso y reconocimiento de la masa y los problemas que a ésta interesan: problemas discutibles, ligados a la existencia, etc. En suma, por tanto, parece que si la filosofía no retoma el diálogo con la religión, cuando mínimo como diálogo polémico, al modo, por 
ejemplo, de la gran filosofía del siglo pasado: Marx, Comte, Nietzsche... se esteriliza y rigidifica perdiendo sentido: se convierte a lo sumo en algo parecido a muchos de esos departamentos de nuestras Facultades Universitarias, reducidos al estudio de cuestiones historiográficas o eruditas, más exigentes cuanto más vacías y normalmente a costa del pensamiento crítico y filosófico.

Por todos estos motivos también externos no me siento - ¿cómo decirlo?como alguien que asistiera pasivamente al retorno de lo religioso, que efectivamente se ha dado en este último tiempo de modo tan considerable como para no poder ser dejado de tener en cuenta. El problema está en que, a menudo, ese retorno me parece demasiado inspirado por motivos, digamos, de megafonía, de integración y regresivos: se retorna a la disciplina católica, se vuelve a la disciplina de la Iglesia, se retorna a la comunidad propia, etc. Por el contrario, cuanto más considero mis motivaciones religiosas, más tiendo a situarme en esa religión de carácter paradójico que se orienta por la dirección de la consunción de la metafísica y se posiciona contra toda normativa dogmática. Acuérdate de las polémicas del Creer que se Cree contra la Iglesia disciplinaria. Todo esto me parece bastante legítimo. ¿Y a ti?, ¿te parece que he contestado, en lo posible ahora, a tus preguntas?

T. O.-Desde luego. Por otra parte, se trata ahora de tener el placer de escucharte hablar libremente y casi sin interrupción...

G. $V$.-En el libro discutes sin embargo esencialmente, en mi opinión, la legitimidad de encontrar apoyo en Nietzsche y Heidegger, a través del nihilismo, para lo que tú resumes como "la radicalización de la hermenéutica por la via del giro hacia un cristianismo kenotistar. Sí, hay mucho que discutir en este punto. Para empezar se podría decir, me parece, que tanto en Nietzsche como en Heidegger hay muchas huellas de un cristianismo cancelado, en el doble sentido de velado o escondido, y de interrumpido. Por lo que se refiere a Nietzsche, no se trata ni única ni principalmente del núcleo bien conocido que ya subrayaba la investigación de K. Jaspers: la voluntad de imitar las Escrituras en el Zaratustra, etc.; todo eso me interesa relativamente, en el sentido de que, como sabes, yo a Nietzsche lo leo a través de Heidegger, y a Heidegger a través de Nietzsche. He dado lugar a este juego de perspectivas e interpretaciones porque me parece abrir y precisar, en ambos, la problemática del sentido de la crítica de la metafisica como historia del ser. Pues bien, desde ese punto de vista, en el caso de Heidegger está claro que hay una imbricación cristiana de las raices de su comprensión de la temporalidad, desde la cual se abre precisamente 
una comprensión no metafisica del ser, interrumpida luego misteriosamente. ¿Por qué no la continuó? Cuando se leen los escritos de Heidegger correspondientes a los años que van del 20 al 27, no se puede localizar con precisión en qué momento se haya cancelado el discurso cristiano, pero ¿por qué?. De acuerdo con la conferencia Fenomenología y Teología, parecería tratarse de una especie de vuelta al neokantismo, o sea: está la filosofía que se ocupa de la investigación del horizonte transcendental, y después están las ciencias positivas entre las cuales, de modo especial, figura la teología que es la ciencia de la fe y de las cuestiones a ella relativas; $y$, sin embargo, desde el punto de vista del Heidegger de Ser y tiempo, que se está preparando para la Kehre, ¿resulta posible seguir pensando la filosofía como teoría del horizonte transcendental. Podría dudarse si no fuera porque eso es lo que precisamente ha negado el propio Heidegger, a partir de la recensión a Jaspers del año 19-20 y del Curso sobre Fenomenología de la vida religiosa del año posterior (20-21); así que no resulta tan fácil entender cómo podría - por así decir- estar usando la «escala» del Evangelio o del Nuevo Testamento precisamente para cancelar o interrumpir su cristianismo. Lo cierto es que en estos mismos libros late siempre implícito el hecho de que no se puede tomar una experiencia religiosa como experiencia ejemplar trasladada a cualquier otra experiencia distinta. Se trata de esa experiencia que está ahí, de ésa como tal, en su concreción. Y, en la misma dirección, la producción en torno a Ser y tiempo, y el discurrir mismo de este texto, expresan tanto las implicaciones como el rechazo de toda posición panorámica, kantiana o postkantiana,, en relación a unas facultades humanas de carácter esencial, idéntico, etc. Por lo tanto, si su pensamiento sobre la temporalidad auténtica u originaria se forma en relación a una meditación sobre la experiencia cristiana, ¿cómo habría podido estar liberándose a la vez de esa misma experiencia? Podría defenderse que sí lo hubiera hecho en la dirección de Fenomenología y teología (1927), pero el discurso racional, desde el punto de vista aludido, no habría podido abstraer la experiencia religiosa, la del teólogo o la del filósofo, de su determinada concreción histórica, del mismo modo que no habría podido abstraer la concrección o historización de la experiencia de la fe. Sin duda hay otros muchos factores implicados en estas investigaciones, pero este conflicto dibuja un hilo conductor tan marcado en el Heidegger de esos años, que todo parece terminar por girar alrededor del mismo. Parece, en suma, que en Heidegger lucharan una posición fenomenológico-kantiana y una existencialista-ontologica. En algunas ocasiones parecería que dominara la primera - y éste es el problema-, pero cuando lo hace entra en conflicto con su 
posición original, contraria a la de Husserl, al darse de las cosas objetivas tal y como se dan a la conciencia depurada, etc. No se puede dejar esto de lado; cada vez me parece por ello menos acertado el tipo de interpretación que sitúa a Heidegger cerca de la fenomenología, digamos pacíficamente, omitiendo las tensiones de este nudo aporético.

No sé si has leído aquél texto tan conocido de Schürman: El principio de anarquía. Lo digo porque he discutido arduamente con él. También he sido amigo suyo y le recuerdo con mucho afecto, pero me confronto con su discurso como con una referencia crítica habitual, porque siendo así que comparto toda su construcción sobre el fin de los archaí, no puedo compartir la suerte de final fenomenológico donde desemboca. Se trata de una especie de conclusión fenomenológico-mistica, como si para Schürman se pudiese estar contemplando la no contemplabilidad del ser, termina por llegar a un punto que me parece contaminado o inspirado, una vez más, por la fenomenología: los archaí, sí, se disuelven, pero al final ¿̇hacia qué?... hacia una liberación del ser captado por una mirada mística orientada a la inmovilidad... y esto... esto es algo dudoso, también porque en Schürman mismo hay otro aspecto comprometido por esta cuestión y que afecta, sin duda a la ética; por ejemplo, cuando habla de la economía de las épocas - lo cual hago yo también y en esto me vuelvo a encontrar cerca-, hallando, como lo hace, un hilo conductor en la historia del ser, pone, en el fondo, el acento en las épocas, y habla mucho más de éstas que de la historia, por lo que viene a situarse en una perspectiva, digamos, relativamente relativista, ya que las épocas son diversas; mientras que, después, el final de los archaí, implica una suerte de perspectiva o mirada simultánea sobre la multiplicidad, y esto no puede dejar de evocar, de nuevo, al sujeto metafísico suprahumano, que mira la multiplicidad desde fuera, quedándose fuera de ella.

Por tanto - ¿cómo diría? - eso que encuentro fundamental en Heidegger es justamente su origen enraizado en la tradición cristiana, ese origen suyo que él después ha cancelado, seguramente, por distintas razones: una, porque cuando se hace nazi se hace nazi, pero ya en el año 23 , cuando estudia a San Agustín, está la idea de que el Cristianismo de los origenes, el de San Pablo, el de los tesalonicenses, etc., nada tiene que ver con su decadencia escolástica. Así pues, no se puede decir que Heidegger cancelase el Cristianismo de los orígenes porque hubiera devenido metafisico: esto es un disparate que no se puede sostener, siendo así que estaba estudiando a San Pablo en el año 20-21, y además lo estudiaba con intensidad. Sin embargo, en mi opinión, esta cuestión ni 
se entiende bien ni se explicita de modo suficiente en ninguno de los escritos de estos años, entre el 20 y el 27; se mezcla con una especie de excedente que se repite: "kantismo", "neokantismo», etc., y que, sí, se acompaña, desde luego, con la idea de un retorno a los griegos, pre-socráticos, pre-metafísicos... pero yo encuentro todo esto más bien inauténtico, es decir, más bien innecesario, aunque no quepa duda, claro, sobre que esto sea también heideggeriano. No, no lo niego, pero, en mi opinión, todo este énfasis puesto en buscar la palabra originaria de los griegos es una cuestión de profesores, digamos la verdad, de universitarios, de aquellos que van a hacer cursos en la Universidad, que van a estudiar a Platón... Pero ¿qué hacemos con ello?, ¿qué se puede hacer con ello? El escrito Platos Lebre von der Warheit es del 43, y hay desde luego todo ese trabajo suyo sobre los griegos... pero estaba ya antes: la esencia de la verdad para Platón constituye el inicio de la historia de la metafísica, de la visualidad... y su crítica estaba ya en Dilthey, cuando éste se preguntaba por medio de San Agustín si se podía hacer devenir real lo verdadero subjetivo, etc. Este es justamente, en mi opinión, el punto conflictivo, porque, de algún modo, Heidegger podía encontrar en el enlace con los griegos, y en la continuidad con la cultura antigua, una cierta autoridad del tiempo... además de estar él mismo también algo fascinado por la visibilidad de Platón, por las Ideas... En el fondo creo que de Heidegger se podría pensar lo mismo que Dilthey piensa de San Agustín, a saber: que quería realizar activamente las Ideas. Heidegger era activo y tenía ese sueño político descabellado: el de las juventudes alemanas, el del célebre Rectorado; en realidad estaba verdaderamente fascinado, por las razones que fueran, y hasta el punto de dejarse poseer efectivamente por ella, por esta idea, no tanto de la visualidad platónica, a la cual él mismo sometería a crítica, pero sí, en suma, por un darse originario, presencial de la physis.

Estas cosas escribe Heidegger, pero yo desde luego, confieso que no sólo ahora, sino nunca, en ningún momento, he comprendido nada de esto: siempre me ha dejado como si tal cosa, del todo indiferente, y supongo que algo así puede resultar extraño para los que estudian dicha vertiente de Heidegger y lo leen desde ese punto de vista, pero, a mí... a mí lo que me parece importante, por el contrario, no está ahí, sino en proseguir el discurso de la Kehre. Porque lo que es cierto a posteriori, una vez que Heidegger ha terminado de escribir y que su escritura no puede ya verse modificada, es que resulta más fácil una mirada unitaria sobre su obra y el sentido de su obra. ¿Qué es la Kehre? - un pasaje, una vuelta. el fin de la consideración de la existencia en términos abstractos, universales, y el inicio del discurso sobre la historia de la metafísica... 
Los "existenciarios" de Ser y tiempo, lo "auténtico" e "inauténtico», etc., devienen caracteres de la historia del ser. Aquí nace toda la cuestión del Heidegger historicista, determinista, etc. Pero véase que la Kehre adviene en el año 30, cuando Heidegger escribe la Introducción a la Metafisica, o sea, cuando dice que América, Rusia, Europa o Alemania son equivalentes en el sentido de ser las grandes entidades que condicionan la existencia individual - lo cual no es poco-; y ello porque toma conciencia de cómo se trata de potencias históricas que desmienten la idea de una naturaleza humana siempre igual, de una existencia siempre articulada según los mismos esquemas que todavía regían sobre los «existenciarios. Como he escrito en mi libro del 63, Essere, storia e linguaggio in Heidegger, eventualiza entonces los "existenciarios, que devienen, por tanto, especies del evento, del Ereignis. No veo por qué se debería alterar o modificar esta lectura, esta interpretación, porque, en último término, sí, hay ciertamente otras lecturas de Heidegger, más sensibles a tales o cuales otros aspectos de su obra: a los escritos sobre Parménides, a los cursos sobre Heráclito..., pero ¿hacia dónde se orientan?

T. O.- ¿Cómo habría de leerse, entonces, la apelación de Nietzsche y Heidegger a la filosofía griega no metafisica?

G. V.-Sí, está claro que el hacia donde condiciona completamente la filosofía de línea "no metafisica", tal como preguntas. Pero, para mí, toda esa dimensión del digamos Heidegger griego no es tan importante para una filosofia no metafisica, no me parece que tenga tal relevancia. Me lo pregunto, efectivamente, y no alcanzo a ver en la literatura heideggeriana corriente los frutos de ese énfasis sobre su consideración de la "filosofía griega no metafísica", etc. Desde luego están todas esas grandes palabras auráticas, que, sin embargo, para mi gusto, dan idea más bien de un cierto heideggerismo contemporáneo, pero no veo el fruto de esta lectura alternativa, porque me parece que, a fin de cuentas, se trata de un "heideggerismo filo-presocrático", que da juego a un Heidegger anti-moderno, anti-sociedad-de-masas , anti-... pero esto casi parece dibujar una caricatura de Heidegger: el Heidegger de la Selva Negra, el pensador aurático, etc. $\mathrm{Al}$ mismo tiempo debo decir, sin embargo, que puede darse que seas tú en ocasiones quien tenga razón en la crítica, cuando estimas que yo estoy demasiado preocupado por las consecuencias político-culturales y éticas del pensamiento; una de las razones por las que me parece más razonable leer a Heidegger desde el punto de vista del pensamiento débil en vez de leerlo desde el punto de vista "aurático", está, en efecto, en que me parece más útil, más utilizable. Piensa que alguien como Gadamer, que no conocía mal a 
Heidegger, le ha leído, digamos, todavía peor que yo, en el sentido de haberlo urbanizado hasta el punto de convertirlo en una base de apoyo para el renacimiento de la filosofia práctica: de la prudencia, de la tolerancia... Yo sin embargo he visto, desde luego, algo más, y he ido más lejos... Es curioso, pero con respecto a Gadamer me siento menos debolista. Gadamer, por ejemplo, no habla de la "historia del sen", aunque parece claro que intervienen aquí factores también contextuales. Los alemanes ya han sufrido demasiado con el, digamos, malentendido de Heidegger cuando se hizo nazi, como para no intentar mantenerse a distancia y tender a posiciones políticamente distantes; el propio Heidegger salió profundamente malparado de aquella experiencia. Pero, de todos modos, en discusión con Gadamer, no pienso que se pueda hacer de Heidegger un mero teórico de la razón práctica aristotélica, enfocándose ésta, además, bajo el sesgo de una cierta filosofia de la tolerancia, por mucha importancia que a la tolerancia se conceda; en Heidegger no se puede elidir el planteamiento ontológico. Yo leo a Heidegger, por contraste, queriendo hacer de él, o inclinándome a encontrar en él un pensador de la emancipación, sí, pero a través de la dirección del Evento.

Hay una hermosa frase que he leído mucho en este último tiempo, y a cuya comprensión crítica he dedicado hace poco un breve ensayo, que he escrito para la Revista Internacional de Filosofia; te he traído una copia en francés, para que podamos comentarlo juntos en otro momemto; se trata de aquella frase del último párrafo de la primera sección de Sein und Zeit, cuando Heidegger dice: "Sein — nicht Seindes- "gibt es" nur, sofern Warheit ist. Und Warheit ist nur, sofern und solange Dasein isti. Pues bien, discutiendo con Gadamer, yo propongo leer esta frase en términos normativos, esto es: hay el ser, y no el ente; el ser se da sólo en la medida en que el ente es reducido, alejado, es decir, en el momento en que viene negada su imposición en cuanto presencia - porque esto es lo que afecta al discurso sobre la violencia y la no-violencia. El ser aparece sólo cuando hay verdad, pero la verdad no es la realidad, es algo muy distinto; incluso razonando en términos como los de un analítico un poco neokantiano y algo hermenéutico como es $\mathrm{N}$. Dauer, tiene interés descubrir que dice cosas muy parecidas a las que decimos también nosotros, los hermenéuticos; porque para Dauer la verdad tampoco se da como mero reflejo del dato, sino que se da cuando se inserta la experiencia del dato dentro de un contexto, que él piensa luego de acuerdo con las formas a priori kantianas, aunque, al parecer, crea que éstas se pueden modificar en todo caso dentro del tejido de la realidad lingüística. Pues bien, en este último sentido estoy de acuerdo, claro, hoy 
resulta difícil no compartirlo. Sin embargo, hay algo más en ese "ser, no ente" que puede devenir también - ¿cómo decirlo? - una suerte de línea directriz, de carácter ético-emancipatorio, si se piensa que el sentido de la civilización humana está en liberarse de la fuerza de imposición de la inmediatez del dato, hacia lo que a mí me parece ser una especie de espiritualización, una reducción de la realidad, una virtualización. La "técnica" es esto, la «sociedad de derecho" es esto, en la medida en que el derecho es un modo de limitar la inmediatez de la venganza, por ejemplo, y, análogamente, formas inmediatas de violencia en otros tantos casos. Hablo aquí de una preocupación práctica, ético-política, si quieres, aunque no en sentido "edificante", porque si lees, por ejemplo, un libro como el de J. Grondin sobre la hermenéutica, y en especial sobre la hermenéutica de Gadamer, insistiendo en cómo para éste y también para Heidegger las verdades son siempre históricas, y en consecuencia se debe ser tolerante... dirás con razón: "ya, claro, pero... ¡sólo esto?; ¡me parece verdaderamente demasiado pocoh; es cierto que ofrece una lectura comunitaria, sí, y abierta, en el sentido corriente de que no hay nunca un confín claramente definido... pero, en fin, argumentos de ese estilo...

Por tanto, encuentro que la validez de mi lectura de Heidegger también resulta defendible desde el punto de vista de una determinada preocupación ético-política, la cual, claro está, no es sin embargo, la misma de Heidegger, por lo que resultaría posible objetar, entonces, que estuviera equivocado al adoptar tal perspectiva. La cuestión inicial volvería, pues, a reproponerse: ¿a donde quería llegar Heidegger? ¿Quería llegar de nuevo - y retomo la disyuntiva que considerábamos hace un momento-, quería desembocar en una visión del ser más objetiva, más descriptiva, más reflejante, más fiel, o quería, por el contrario, una visión del ser éticamente más aceptable desde el punto de vista humano? Pero tampoco se puede olvidar que no podría quererla en nombre de una humanidad general, porque habría recaído o habría continuado manteniendo una posición esencialista respecto del hombre, sino, antes bien, en nombre de una cierta tradición en cuyo contexto se situaba y que leía de un cierto modo; no veo que sea una interpretación abusiva. Luego está mi aplicación de este complejo de cuestiones a la teoria de la modernidad como debilitamiento, como secularización, etc., y mi lectura de nuestros problemas actuales desde la clave de una lucha entre el exceso de realismo y la denuncia de que no somos aún lo bastante nihilistas porque seguimos creyendo que lo verdadero es lo real.

Se trata, en cierto modo, de eso mismo que concernía a W.Benjamin en el discurso del 36 sobre la «reproductibilidad» (de la obra de arte), cuando 
analizaba el efecto desfondante de los valores de mercado. Al hablar de mercado se habla a menudo como si se tratara de algo real, mientras opera el mecanismo de esa pura circulación del cambio tendente a la nihilidad. Desde luego, si desde el punto de vista del principio de realidad hubiera alguien que pretendiera controlar el mecanismo económico, fracasaría estrepitosamente; pero ¿es que debería funcionar el principio de realidad? Si quieres que la banca norteamericana condone la deuda de los países sudamericanos, por ejemplo, renunciando a cobrar la restitución, debe mantenerse en pie la defensa de una economía imaginaria, y no sólo porque ésta sea la única que rige; éste es uno de los sentidos posibles del discurso sobre el debilitamiento de la "presencia" del ser; y es este tipo de preocupaciones, que explican mi orientación activa a favor de la disminución de la violencia en todos los órdenes lo que me ha conducido ahora a ser diputado europeo, ¡a pesar, eso sí, de que económicamente no me convenga! Es verdad que de niño soñaba a veces con ser político, con transformar el mundo, pero también es verdad que podría haber suscrito esa declaración de Nietzsche cuando, en aquella carta de Torino fechada en enero del 89, decía que estaba mucho más contento de ser profesor de Filología en Basilea de lo que habría podido estarlo de haber sido un dios; sí, pero quizá resulta demasiado cómodo dejar a parte esas preocupaciones éticas y políticas, habiendo como hay en ellas un cierto sentido irrenunciable, por mucho que de niños lo intuyamos sólo, digamos, de un modo impuro... mezclado con ilusiones de grandeza, etc. Pero tampoco parece que este tipo de preocupación ético-política de origen religioso haya sido ajeno a Heidegger, si bien de un modo muy distinto, a lo largo de toda su vida.

T. O.- ¿Cuál es el marco preciso en que se inscribe la invitación al debilitamiento, fundada ontológicamente, a través de tu interpretación del envío que se lee en la filosofia de la historia nibilista? ¿Tiene sentido más allá del área geopolítica del Occidente hegemónico?

$G$. $V$ - -Sí, éste es otro de los puntos sobre el que tanto se discutió la última vez que nos reunimos en Madrid; he pensado luego mucho en ello, y me parece lógico que la condición española sea particularmente sensible a los problemas transculturales, en ese sentido se debe decir que hay una clara diferencia histórica entre vuestra condición como españoles y la mía como italiano. En Italia, por ejemplo, la cultura musulmana no ha tenido nunca la presencia y la importancia que ha tenido en España; ésta es una corrección relevante que estoy dispuesto a aceptar; pero debo aceptarla, no, digamos, intentando colocarme en 
una posición super partes, sino intentando verla desde el interior de mi cultura. Por lo demás, el problema de la otra cultura se plantea a la Europa cristiana cuando se encuentra con el mundo islámico; asunto que en España había sucedido ya antes del año mil, mientras que para el resto de Europa hubo de esperar al tiempo de las Cruzadas, por tanto, también este problema de encuentros es un problema que nace de una situación histórica determinada. Hoy, por ejemplo, en nuestra situación histórica, que es la del mundo tecnológicamente occidental, es cierto que nos encontramos con otras muchas tradiciones culturales y religiosas, no sólo ya las musulmanas, sino también las indo-americanas, las budistas, las hindúes, etc. Pues bien, yo tomo conciencia de ello justo desde el punto de vista del Cristianismo, porque estoy convencido, por ejemplo, de que al igual que Dios se ha hecho hombre, puede hacerse también gato, pájaro, serpiente o Buda; lo que quiero decir es que la salvación del Cristianismo, tal y como yo la interpreto en el sentido del debilitamiento, consiste hoy, justamente, en el contaminarse con otras religiones y en no pretender nunca más "convertir» al prójimo; pero esto lo pienso - ¿cómo decir?- - con el alcance de una meditación ontológica, y no como si se tratara de mitos parciales, tal como harían, podríamos suponer, por ejemplo, los misioneros, que originariamente partían ya predispuestos en contra de estos mitos de los otros, o bien se ponían demasiado de parte de Pizarro o de Cortés; es decir, que convertían a los indios mientras se ponían de parte de los conquistadores, y entonces también de paso les convertían a la causa de los conquistadores, pero es obvio que sin llegar a entrar en contacto con ninguna religión como tal. Estoy, así pues, bastante seguro de que hay razones hoy no para ser occidento-céntrico, eso desde luego, pero sí para defender paradójicamente muchos de los puntos de vista de Occidente precisamente contra el etnocentrismo; yo soy tolerante y siento verdadera curiosidad por otras culturas con las cuales desearía entrar en contacto, porque he aprendido antropología cultural en Occidente, y lo cierto es que siempre que los otros se muestran, por su parte, disponibles al acercamiento que supone cualquier modo de discurso, me embarco en el acto. Tengo una visión de Occidente como Abendland, como la tierra en la cual el ser se fragmenta, se disuelve, se deshace... y este es el único modo en que puedo seguir siendo occidental sin fingirme que soy otro y sin ir en contra de los otros, porque hay en mí y yo soy de ella portador, una cultura que no es «decadente» sino, hablando en propiedad, auto-disolvente, y lo es en tantos sentidos...: el poder político que ha devenido democrático se distribuye y dispersa; la misma psicología individual es cada vez menos compacta y más plural... —_entiendes? -; puede parecer 
una posición abstracta pero, al contrario, viene a consistir en una posición que deriva de la idea de estar siempre en el interior del evento, y nunca pretender, universalistamente, juzgarlo desde arriba, desde fuera o desde lo otro ajeno a aquello de lo que se trate.

Estas son, naturalmente, cuestiones que no se resuelven sólo teóricamente, como tampoco, por otra parte, nuestro discurso sobre la historia del ser. Indudablemente, Heidegger no podía pensar el debilitamiento del ser en esos términos, sino de acuerdo con la articulación y el contexto posible de alguien que vivia en Europa y en Alemania después de la Primera Guerra Mundial. Con todo, son muchas las ocasiones en que insiste, de igual modo, en que el pensamiento no puede corregir el curso del ser; no tendría sentido... Nosotros estamos efectivamente dentro y en el curso de un proceso que ciertamente tiene lineas de orientación. Es verdad que decir que hay tales hilos conductores resulta aún bastante insatisfactorio, porque incluso dentro del proceso de la civilización occidental, del encuentro con otras culturas, etc., ¿cómo se hace para preferir y escoger una cosa más bien que otra? Es en este punto donde se imbrica el discurso de la posición: es verdad que yo estoy siendo en un curso de procesos violentos, al cual no miro desde fuera, sino desde dentro, haciendo una labor de interpretación de la realidad; esto es, mi voluntad se implica en la propuesta que se traduce en decir que la modernidad, para mí, es la debilitación del futuro fuerte, con ello propongo ya una lectura de la modernidad que quizá pueda ser contestada por otros, pero que se arriesga a serlo, y, como mínimo, no podrá ser rebatida en nombre de los hechos, por nadie que dijera: "muy bien, hasta aqui llega tu interpretación, pero los hechos son distintos, y los hechos son la verdad..." ¡Eso sí que no!, porque si alguien me habla de la verdad en esos términos, entonces ¡saco la pistola! ¡Es demasiado! Nosotros somos únicamente intérpretes de un hilo conductor... Y aunque hay muchos estudios que se preguntan hoy por el problema de la posición, olvidan demasiado a menudo, creo, que se trata quizá de una posición un tanto móvil. Por lo cual, y en relación al Occidente hegemónico, digamos que estoy convencido de que resulta necesario contribuir a que se consuma ese carácter hegemónico a través también, por ejemplo, de la disolución o el debilitamiento de sus instituciones culturales: la Iglesia, los poderes, una cierta forma de hacer la política... cosas todas las cuales hacen muy difícil ocuparse del individuo. Es cierto que tú concedes un amplio espacio a esta problemática en tu discurso, y que la postmodernidad que tú declinas resulta particularmente sensible a estas cuestiones; luego, como buena seguidora de Deleuze, terminas por localizar la clave de la hegemonía en 
la idea de disolver incluso la soberanía del individuo en cuanto sujeto, lo cual entraña, sin duda, muchos riesgos en las sociedades de masas... pero esto nos haría entrar en otra cuestión, que merece ser tratada por separado y necesita partir de varias distinciones, entre ellas, también, las relativas a los contextos...

T. $O$. - ¿Cuál es el marco preciso en que se inscribe la invitación al debilitamiento, fundada ontológicamente, a través de tu interpretación del envio que se lee en la filosofia de la historia nibilista? ¿Tiene sentido más allá del área geopolítica del Occidente hegemónico?

G. V.-Sí, éste es otro de los puntos sobre el que tanto se discutió la última vez que nos reunimos en Madrid; he pensado luego mucho en ello, y me parece lógico que la condición española sea particularmente sensible a los problemas transculturales; en ese sentido se debe decir que hay una clara diferencia histórica entre vuestra condición como españoles y la mía como italiano. En Italia, por ejemplo, la cultura musulmana no ha tenido nunca la presencia y la importancia que ha tenido en España; ésta es una corrección relevante que estoy dispuesto a aceptar; pero debo aceptarla, no, digamos, intentando colocarme en una posición super partes, sino intentando verla desde el interior de mi cultura. Por lo demás, el problema de la otra cultura se plantea a la Europa cristiana cuando se encuentra con el mundo islámico; asunto que en España había sucedido ya antes del año mil, mientras que para el resto de Europa hubo de esperar al tiempo de las Cruzadas, por tanto, también este problema de encuentros es un problema que nace de una situación histórica determinada. Hoy, por ejemplo, en nuestra situación histórica, que es la del mundo tecnológicamente occidental, es cierto que nos encontramos con otras muchas tradiciones culturales y religiosas, no sólo ya las musulmanas, sino también las indo-americanas, las budistas, las hindúes, etc. Pues bien, yo tomo conciencia de ello justo desde el punto de vista del Cristianismo, porque estoy convencido, por ejemplo, de que al igual que Dios se ha hecho hombre, puede hacerse también gato, pájaro, serpiente o Buda; lo que quiero decir es que la salvación del Cristianismo, tal y como yo la interpreto en el sentido del debilitamiento, consiste hoy, justamente, en el contaminarse con otras religiones y en no pretender nunca más "convertir" al prójimo; pero esto lo pienso - ¿cómo decir? - con el alcance de una meditación ontológica, y no como si se tratara de mitos parciales, tal como harían, podríamos suponer, por ejemplo, los misioneros, que originariamente partían ya predispuestos en contra de estos mitos de los otros, o bien se ponían demasiado de parte de Pizarro o de Cortés; es decir, que convertían a los indios mientras se ponían de parte de los conquistadores, y entonces 
también de paso les convertían a la causa de los conquistadores, pero es obvio que sin llegar a entrar en contacto con ninguna religión como tal. Estoy, así pues, bastante seguro de que hay razones hoy no para ser occidento-céntrico, eso desde luego, pero sí para defender paradójicamente muchos de los puntos de vista de Occidente precisamente contra el etnocentrismo; yo soy tolerante y siento verdadera curiosidad por otras culturas con las cuales desearía entrar en contacto, porque he aprendido antropología cultural en Occidente, y lo cierto es que siempre que los otros se muestran, por su parte, disponibles al acercamiento que supone cualquier modo de discurso, me embarco en el acto. Tengo una visión de Occidente como Abendland, como la tierra en la cual el ser se fragmenta, se disuelve, se deshace... y este es el único modo en que puedo seguir siendo occidental sin fingirme que soy otro y sin ir en contra de los otros, porque hay en mí y yo soy de ella portador, una cultura que no es "decadente" sino, hablando en propiedad, auto-disolvente; y lo es en tantos sentidos...: el poder político que ha devenido democrático se distribuye y dispersa; la misma psicología individual es cada vez menos compacta y más plural... - ¿entiendes?-; puede parecer una posición abstracta pero, al contrario, viene a consistir en una posición que deriva de la idea de estar siempre en el interior del evento, y nunca pretender, universalistamente, juzgarlo desde arriba, desde fuera o desde lo otro ajeno a aquello de lo que se trate.

Éstas son, naturalmente, cuestiones que no se resuelven sólo teóricamente, como tampoco, por otra parte, nuestro discurso sobre la historia del ser. Indudablemente, Heidegger no podía pensar el debilitamiento del ser en esos términos, sino de acuerdo con la articulación y el contexto posible de alguien que vivia en Europa y en Alemania después de la Primera Guerra Mundial. Con todo, son muchas las ocasiones en que insiste, de igual modo, en que el pensamiento no puede corregir el curso del ser; no tendría sentido... Nosotros estamos efectivamente dentro y en el curso de un proceso que ciertamente tiene lineas de orientación. Es verdad que decir que hay tales hilos conductores resulta aún bastante insatisfactorio, porque incluso dentro del proceso de la civilización occidental, del encuentro con otras culturas, etc., ¿cómo se hace para preferir y escoger una cosa más bien que otra? Es en este punto donde se imbrica el discurso de la posición: es verdad que yo estoy siendo en un curso de procesos violentos, al cual no miro desde fuera, sino desde dentro, haciendo una labor de interpretación de la realidad; esto es, mi voluntad se implica en la propuesta que se traduce en decir que la modernidad, para mí, es la debilitación del futuro fuerte; con ello propongo ya una lectura de la modernidad que quizá 
pueda ser contestada por otros, pero que se arriesga a serlo, y, como mínimo, no podrá ser rebatida en nombre de los hechos, por nadie que dijera: «muy bien, hasta aqui llega tu interpretación, pero los hechos son distintos, y los hechos son la verdad.... ¡Eso sí que no!, porque si alguien me habla de la verdad en esos términos, entonces ¡saco la pistola! ¡Es demasiado! Nosotros somos únicamente intérpretes de un hilo conductor... Y aunque hay muchos estudios que se preguntan hoy por el problema de la posición, olvidan demasiado a menudo, creo, que se trata quizá de una posición un tanto móvil. Por lo cual, y en relación al Occidente hegemónico, digamos que estoy convencido de que resulta necesario contribuir a que se consuma ese carácter hegemónico a través también, por ejemplo, de la disolución o el debilitamiento de sus instituciones culturales: la Iglesia, los poderes, una cierta forma de hacer la política... cosas todas las cuales hacen muy difícil ocuparse del individuo. Es cierto que tú concedes un amplio espacio a esta problemática en tu discurso, y que la postmodernidad que tú declinas resulta particularmente sensible a estas cuestiones; luego, como buena seguidora de Deleuze, terminas por localizar la clave de la hegemonía en la idea de disolver incluso la soberanía del individuo en cuanto sujeto, lo cual entraña, sin duda, muchos riesgos en las sociedades de masas... pero esto nos haría entrar en otra cuestión, que merece ser tratada por separado y necesita partir de varias distinciones, entre ellas, también, las relativas a los contextos...

T. O.-En cuanto a la cuestión del sujeto, no puede omitirse aquí la referencia a aquél texto tuyo del 81: Más allá del sujeto (Nietzsche, Heidegger y la hermenéutica). Que el sujeto no es sencillamente el individuo involucra la urgencia de pensar las comunidades y lo comunitario desde parámetros tan complejos como inéditos: postmarxistas, postestatales, telemáticos, etc. Sin embargo, no nos queda apenas tiempo, Gianni, así que muy brevemente: ¿qué relaciones posibles te parecen dibujarse entre los significantes politica, moral, arte y cultura, al menos al comienzo del siglo XXI?

$G$. V.-En cierto sentido son términos entre los cuales no me parece haber hoy demasiada diferencia, o, al menos, no la diferencia con que la tradición metafísica trazaba fronteras de separación entre ellos. Para ésta valían las diferencias entre arte y moral (de Kant a Croce), y, por tanto, también las diferencias entre arte y política; mientras que la cultura resultaba vigente como ámbito comprehensivo de todas estas formas de vida espiritual. A mí me parece que hoy se asiste, sobre todo, a una significativa unificación de los tres ámbitos, bajo la categoría general de Weltanschauung. Me viene a la memoria la sección final del escrito de Husserl sobre la Filosofia como ciencia estricta, que me parece 
un ejemplo emblemático de esas distinciones metafísicas hoy insostenibles. Husserl distingue la Weltanschauung de la ciencia, manifestando una preferencia moral por quienes en vez de intentar construir una cierta unidad ejemplar, ya sea con la propia personalidad, ya sea con una cultura determinada, se dedican a la investigación de las verdades científicas que constituyen las etapas ascendentes en el camino del hombre hacia la verdad total... El hombre de la Weltanschauung, sin embargo, es más bien un esteta, mientras que el verdadero filósofo, para Husserl, que es el hombre ético por excelencia, es aquél que renuncia a su perfección personal y piensa sólo en lo eterno, en contribuir a la ciencia. Resulta difícil, incluso desde el ámbito puramente ético, justificar la preferencia husserliana por lo que dura más: ¿por qué los muchos que vendrán después de mí y de nosotros deberían valer más que nosotros, los que estamos hoy aquí? Pero lo que ya no rige hoy en ningún sentido es esa división entre la ciencia destinada a lo eterno y la Weltanschauung restringida a la existencia actual, de carácter estético. Nuestra cultura es ya un fenómeno estético, cuando menos en el sentido de cómo la apertura del ser se articula ahora desde ella misma sin referencia necesaria a ninguna estructura verdadera o permanente, cuya estable duración le sirviera de base y criterio. La moral, ahora, es el arte de construir la unidad de la apertura, esto es, de la cultura, en una forma reconocible, coherente, satisfactoria desde el punto de vista de la transmisión y comprensión de su sentido, $y$, por lo tanto, provista de una continuidad discursiva visible, sin repetición de estereotipos; según un esquema que recuerda, sobre todo, a la noción hermenéutica de aplicación. En efecto, la continuidad y la libertad de la interpretación-aplicación, implican, por una parte, que no estamos frente a una iniciativa puramente arbitraria; pero también, a la vez, que no respondemos, por otra parte, delante de ningún tribunal del ser, de la razón, o de la verdad última.

No pueden desenvolverse aquí todas las implicaciones que para el modo efectivo de considerar el arte, la política y la moral, se siguen de una formulación de principio semejante. Pero si alguien objetara, sin embargo, que tal declaración se reduce a la propuesta de una simple filosofia de la cultura, habría de contestar que lo indicado, quizá peyorativamente, con esa expresión, es también la única ontología hoy posible, y que tenerlo en cuenta cambia mucho las cosas.

T. O. ¿ ¿Cuál es la diferencia entre la postmodernidad debolista y la racionalidad neo-ilustrada que parece difundirse hoy bajo la forma de un humanismo autoritario y un normativismo generalizado? 
G. $V$ - Creo entender que tú encontrarías insatisfactorio cualquier vínculo entre una ontología de la actualidad como la mía y un cierto pensamiento único, pragmático, reformista... eso que en italiano llamaríamos «buonistas (de bueno) y que vosotros llamais ¿"bienpensante»? El temor de que todo acabe por desembocar en una suerte de conformismo nutrido de buenos sentimientos y de valores democráticos es obviamente un temor fundado. Sin embargo estoy igualmente convencido de otra cosa, y es de que sus riesgos son menores que los del fascismo auténtico o la dictadura de (y sobre) el proletariado; así que no hay tanto que lamentar. Si no nos gusta, sin embargo, ¿por qué es?; seguramente porque estamos convencidos de que la libertad, o cualquier otro de los valores afirmables de la experiencia, implican novedad, ruptura, e incluso tal vez un cierto grado de conflictividad y riesgo. Comparto todo esto, pero me preocupo también de no aceptar como indiscutibles muchos de los presupuestos que aquí están implícitos. Por ejemplo, el prejuicio típicamente moderno de que la novedad sea un carácter inseparable de la libertad, de la historicidad del existir, etc. Mi expectativa, en suma, esa esperanza que cultivo también incluso cuando busco y encuentro razones para leer a Nietzsche y Heidegger como filósofos postmodernos, estriba en que la generalización de las costumbres (en los varios sentidos del término: hábito, máscara, educación, estilo, costumbre cultural y ética, vestido, etc.), así como también la generalización del consumo, y, en una palabra, la masificación y el acceso cada vez mayor de todos a los medios de comunicación y a los diversos bienes culturales, traiga consigo - y esto no necesariamente sino como una posibilidad activamente canalizada - un impulso, un estímulo de diferenciación. ¿Podríamos pensar que el pasaje, para nosotros, de la prehistoria de la humanidad a la historia de la misma estuviera en el pasaje del conflicto a la discusion, y de la guerra a la pluralidad de los estilos? No tengo miedo del conflicto entre culturas, tengo miedo de que los conflictos que habíamos creído deberse a conflictos entre culturas no hayan sido sino meras guerras por el dominio, el territorio, el alimento, la propiedad... En definitiva, los riesgos del pensamiento único pueden considerarse como riesgos sólo si se adopta como punto de mira un criterio de valoración edificante. Pero, para mí, el criterio discriminatorio es precisamente el del debilitamiento ontológico, o sea, el de la reducción de la violencia. Si la globalización pudiese ser interpretada como un acto de responsabilidad ética y política, sí, pero en el sentido de la reducción de los conflictos competitivos bélicos entre estilos de vida, de arte, y de culturas, sería inadecuado demonizarla...

T. $O$.-Una última pregunta, si te parece, y nos interrumpimos en este punto. ¿Cuál es tu relación personal e intelectual con Gadamer? 
G. V.-Pues verás, yo diría que, en el fondo, prima para mí la figura del maestro sobre la del filósofo. De Luigi Pareyson he aprendido muchísimo, pero no sé si llegué nunca a desear parecerme a él; era un carácter demasiado fuerte para mi gusto, e incluso la discrepancia final entre su pensamiento trágico y el pensamiento débil que he intentado construir parecería reflejar esta diferencia de temperamento. No quiero decir con esto que me vincule a él un menor afecto o estima de los que me vinculan a Gadamer; pero algunas veces pienso en Gadamer como en alguien a quien me asemejo incluso demasiado, por sentirlo y ponerlo como una auctoritas delante de mí... Es curioso, porque si bien no creo que teóricamente Gadamer lo aceptase, manteniendo como mantiene un vínculo tan estrecho con la tradición de la filosofia clásica, lo cierto es que Gadamer, como hombre y como pensador, parece un emblema del pensamiento débil, al menos tal y como yo lo interpreto: una considerable dosis de autoironía y comprensión, unida a la fidelidad hacia el lógos como transmisión de valores de cultura en el sentido del espíritu objetivo hegeliano. Nunca me olvido de cómo Gadamer ha sufrido a lo largo de su vida frenos tan hirientes como el de la poliomelitis, que fue dejando marcas muy relevantes en un cuerpo por otra parte atlético y casi monumental. $\mathrm{Y}$, a menudo, he reflexionado, por lo mismo y por otras muchas razones, en cómo su buen temperamento no se debía a un don natural, sino a ese tipo de disposición largamente conquistada mediante una resistencia sin tregua a la dificultad. Gadamer mismo dice con frecuencia que en lo que más me parezco a él es en ese cierto histrionismo que ambos compartimos; lo cual, dicho con algo más de benevolencia, remite al gusto por estar con los otros: las lecciones, las conferencias, los seminarios, las conversaciones filosóficas... En cuanto a mí, sé que se trata de una consecuencia de mi debilidad e inseguridad de caracter: "la de un hijo que nunca ha devenido padren, como decía Pasolini; pero en el caso de Gadamer, se debería hablar más bien de algo así como de aquél diffusivum sui que el pensamiento escolástico consideraba la cualidad diferencial del bonum.

T. O.-Bonum que es, por eso, cifra del amor y la belleza... Al oírte estaba recordando un texto de Gadamer de 1992: Fenomenología del ritual y el lenguaje, que pone en juego la ontología estética como lazo social comunicativo del virtual, en el sentido de lo mejor de lo posible para cada gesto y acción cotidianos que retornan diferentes... Muchas gracias, Gianni, ha sido un placer. Gracias, otra vez, por tu tiempo, tu generosidad, y la paideía de tu profunda cortesía. 